\title{
SPORT CONSUMPTION PATTERNS IN THE EASTERN CAPE: CRICKET SPECTATORS AS SPORTING UNIVORES OR OMNIVORES
}

\author{
Kelcey Brock* \\ Rhodes University
}

Received: March 2016

\author{
Gavin Fraser* \\ Rhodes University
}

\author{
Ferdi Botha+
Rhodes University
}

Accepted: July 2016

\begin{abstract}
Since its inception, consumption behaviour theory has developed to account for the important social aspects that underpin or at least to some extent explain consumer behaviour. Empirical studies on consumption behaviour of cultural activities, entertainment and sport have used Bourdieu's (1984) omnivore/univore theory to investigate consumption of leisure activities. The aim of this study is to investigate whether South African cricket spectators are sporting omnivores or univores. The study was conducted among cricket spectators in the Eastern Cape at four limited overs cricket matches in the $2012 / 2013$ cricket season. The results indicate that consumption behaviour of sport predominantly differs on the grounds of education and race. This suggests that there are aspects of social connotations underpinning sports consumption behaviour within South Africa.
\end{abstract}

Keywords

Consumption; sport; univores; omnivores; social connotations

*Ms K Brock is a lecturer in the Department of Economics and Economic History, Rhodes University, Grahamstown, South Africa. \#Prof G Fraser is professor in the Department of Economics and Economic History, Rhodes University, Grahamstown, South Africa. +Mr F Botha is a senior lecturer in the Department of Economics and Economic History, Rhodes University, Grahamstown, South Africa. [f.botha@ru.ac.za] 


\section{INTRODUCTION}

Sport is highly regarded among South Africans, both in terms of active participation and in a passive role as a spectator (Brember, 2009). As South Africans place a great deal of recognition on cricket as both an amateur and professional sport (Louw, 2010), this study focuses on the application of consumption behaviour theory in cricket. With South African cricket forming a significant aspect of international cricket heritage (Morgan, 2013), it is important to examine factors that would increase the likelihood of the long-term survival of the game. This could be achieved by investigating the extent to which sporting consumption patterns in South Africa are bound up in social hierarchies by classifying consumers as either sporting univores or omnivores.

Sport forms part of an important industry that significantly affects GDP and, as a result, it is important to ensure that the sports industry be nurtured and maintained (Szymanski \& Kuypers, 1999). In the case of South Africa, the sports industry has been noted as a 'multibillion rand industry' and contributed to $2 \%$ of the country's GDP (South African Web, 2013). Statistics South Africa (2012) also highlights the importance of the South African sports industry in generating significant tourism revenue. Thus, aiding the growth of South Africa's Gross National Sports Product (GNSP), through the positive identification of factors that are correlated to match attendance would likely facilitate South African GDP growth. A final argument grounding the need to increase or sustain a country's GNSP is that generally the global sports industry has a large number of existing employees and has annually been accountable for the creation of a significant number of jobs (Eschenfelder \& Li, 2007). The goals of this study are to investigate whether South African cricket spectators are sporting omnivores or univores and whether certain characteristics can be attributed to these consumption decisions.

\section{THE OMNIVORE/UNIVORE THEORY}

Empirical work on consumption behaviour of different forms of culture has established a definite link between cultural consumption patterns and social stratification (Widdop, 2010). According to Chan and Goldthorpe (2007), the idea of linking cultural consumption to lifestyles dates back to 1964 , where empirical research by Wilensky (1964) suggested that individuals from a high educational background rarely had a strong aversion to culture that was associated with the masses. Wilensky (1964) further noted that highly educated individuals often enjoyed 'mass' culture in at least some of its forms. This relationship, which in essence looked at the prevalence of an omnivore/univore classification in arts, was originally theorised by Bourdieu (1984) in proposing that social status could be used to understand the cultural consumption preferences.

According to Peterson (2005), Bourdieu's (1984) theory was unique in that it proposed a theoretically grounded means of conceptualising the relationship between consumers' tastes, status and social class. Bourdieu (1984) suggested that cultural consumption preferences could be classified according to 'high' and 'low' cultural forms. In order to appreciate 'high' cultural forms, it required one to have high cultural capital, which, inter alia, stems from an individual's upbringing, education and socio-economic background. Bourdieu (1984) noted that these 'high' cultural forms were more likely to be consumed by individuals from high income and high education backgrounds, who were considered to be of a high social class. At the opposite end of the spectrum, 'low' cultural forms, referred to as mass or popular culture, were more likely to be consumed by individuals from lower income and lower education backgrounds and were thus perceived as being of a lower social class. As such, Bourdieu (1984) argued that the appreciation 
of cultural forms was an indicator of social class and owing to the fact that appreciation of 'high' cultural forms required an individual to have high cultural capital, the 'masses' who failed to possess such high cultural capital were essentially excluded from the consumption thereof. Finally, Bourdieu (1984) noted that cultural appreciation, which was essentially indicative of cultural capital, provided a means of judgment of social superiority.

Peterson (1992) contested Bourdieu's (1984) hypothesis that individuals from high income and educational backgrounds would more likely consume 'high' culture forms and individuals from lower income and educational backgrounds would more likely consume 'low' cultural forms. Peterson (1992) argued that while 'high' cultural forms were more likely to be preferred by individuals from high income and high education groups, such patrons had highlighted a preference for a wide range of popular/non-elite musical forms. Peterson's (1992) claim was therefore in line with what Wilensky (1964) had originally suggested. Furthermore, Peterson (1992) noted that individuals from lower education and lower income groups were conversely generally found to appreciate only one genre of music, which was indicative of narrower cultural preferences.

Consistent with Peterson (1992), Lamont (1992) considered whether the relationship between social status and tastes was the same across geographical boundaries, essentially questioning Bourdieu's (1984) claim that high-brow patterns of taste were directly attributed to social class and therefore should be the same in all advanced capitalist societies. Lamont (1992) brought to light the fact that high-brow tastes were not the same in all advanced capitalist societies as Bourdieu (1984) had suggested.

Since Peterson (1992) and Lamont (1992) contested Bourdieu's (1984) hypothesis, a wide array of studies have considered the application of the univore/omnivore theory in various contexts. Such contexts include the cultural context (Alderson, Junisbai \& Heacock, 2007; Chan \& Goldthorpe, 2007; Snowball, Jamal \& Willis, 2009; Antrobus \& Snowball, 2010), the entertainment industry (Chan \& Goldthorpe, 2005; Suominen, 2007) and general leisure consumption (Widdop, 2010). Sports consumption, however, 'remains at large underdeveloped' (Widdop, 2010:2). Empirical studies of the omnivore/univore theory in sport have largely been focused on sports participation (Lefevre \& Ohl, 2011; Widdop \& Cutts, 2013), which has been argued to have a positive relationship to other forms of sports consumption (White \& Wilson, 1999; Wilson, 2002; Thrane, 2001; Mehus, 2005).

For sport participation, Widdop and Cutts (2013) found that omnivores were most likely to be individuals from high social strata and high education backgrounds. Women generally displayed omnivous sports consumption behaviour, while older cohorts generally displayed snobbish taste preferences. Lefevre and $\mathrm{Ohl}$ (2011:48) argued that 'the social ranking of sports is generally not very marked' and, consistent with Widdop and Cutts (2013), found that most distinct differences in terms of sports consumption appear to be in terms of age and gender. In this case, however, univorous traits were relatively more prevalent in women than in men (Lefevre \& Ohl, 2011). Overall, Lefevre and $\mathrm{Ohl}(2011)$ found that univores were predominantly from the lower social classes, while the relatively higher social status individuals were predominantly classified as omnivores. Warde (2006) conducted a similar study but accounted for sport spectatorship. Again, it was found that gender was the 'most powerful discriminating variable' (Warde, 2006:115). Warde (2006) noted that there are some distinctions between classes' choice of sports consumption, particularly evident between individuals at the top and bottom of the class hierarchy in terms of their occupation. 
The contested hypothesis and differences in empirical findings suggested that there is a need for further empirical investigations. This was supported by Scheetz, Dubin and Garbarino (2014:5), who noted that 'while many economists have highlighted the role of social comparison in consumer behaviour, little work has been done to empirically test this idea.'

\section{CLASSIFICATION OF SPORTING OMNIVORES AND UNIVORES}

Bourdieu (1984) highlighted that sport is an object of struggles between social classes. This study investigates the classification of consumers' behaviour in terms of social hierarchy in accordance with what was proposed by Widdop (2010:3):

Certain types of sporting activities such as the golf, racket sports, water and winter sports (classified as highbrow or legitimate culture) would be consecrated among those in the higher classes, whilst others, such as football, tenpin bowling and weightlifting would be avoided through the association with the masses.

This is used in conjunction with Warde (2006), where exclusive sports included racquet sports, water sports and adventure sports in the adaptation of the conventional definition in this context. To account for the two dominant forms of sports consumption (attendance and television viewing), two separate conventional definitions were derived. The rationale for this is underpinned by Widdop and Cutts (2013), where it was noted that it is important to look at reported tastes and actual spectatorship behaviour in order to get a comprehensive overview of the cultural genre (or in this case sporting code).

The first conventional definition focused on consumption of sport in terms of watching the sport in attendance. For this definition (hereafter referred to as Conventional definition-live), consumers were classified as univores if they had exclusive sports consumption patterns. Consumers were assumed to have exclusive consumption behaviour if they attended highbrow/legitimate culture sports or only sports that were associated with the masses and therefore deemed univores. Conversely, consumers were classified as omnivores if they displayed a wide array of consumption behaviour, or if they attended both high-brow/legitimate sports and sports that are associated with the masses. This definition was largely underpinned by Bourdieu's (1984) theory of the appreciation of high and low cultural forms. Drawing from both Widdop (2010) and Warde (2006) and by taking careful consideration of the extent to which consumers would have access to consumption, the following sports (identified by respondents as the sports they choose to watch in attendance) were classified as high-brow/legitimate culture sports: golf, tennis, equestrianism, swimming, motor-sport, rowing, cycling, water polo, and squash. With the exception of equestrianism and golf, each of these sports fell under either a water, racket or adventure sport. Golf was specifically classified by Widdop (2010) as a high-brow/legitimate sport and was therefore classified as such in the derivation of this definition.

Furthermore, for sports that had not been empirically classified as highbrow/lowbrow, a common ground of classification was needed for the derivation of these classifications. This study made use of structural constraints as a common ground of classification. According to Kim and Trail (2010:192), structural constraints are 'factors that interfered between leisure preferences and participation, that is, physical or environmental factors that prevented an individual from leisure participation'. For the purpose of this study, if the venue at which the sport event is generally hosted did not allow for or accommodate large amounts of spectators then the sport was said to exclude the masses and subsequently classified as elitist in nature. For example, a sport such as soccer is generally hosted at large stadia (therefore having the capacity to accommodate masses 
of spectators), whereas a sport like shooting is generally hosted at relatively smaller facilities where the capacity/structural constraint of the venue would not allow for the masses to attend. Following this line of argument, the remainder of the spectator sports that were identified were classified as lowbrow/associated with the masses, and these included soccer, rugby, hockey, and netball.

The second conventional definition (hereafter referred to as Conventional definition-TV) was derived using the same principles as the first conventional definition (i.e. informed by empirical classifications, and where none are evident the remainder of the sports were classified on common grounds) but looked only at consumption in the form of watching television. The following sports were classified as high-brow/legitimate culture sports: golf, tennis, equestrianism, swimming, multi-sport events (particularly the Winter Olympic Games), extreme sport, cycling, motorsport, badminton, squash, shooting, and fishing/surfing. The same argument as applied in the Conventional definition-live was used to support the classification of golf and equestrianism as high-brow/legitimate culture sports.

In order to classify the sports that have not been previously empirically classified, structural constraints (Kim \& Trail, 2010) were again used as the basis of classification. In this case, sports were classified based on the extent to which they are broadcast on television in South Africa. Based on the broadcasting schedules available to television viewers in South Africa (Supersport, 2014; SABC Sport, 2014; ETV, 2014) the following sports (excluding sports that have been previously empirically classified) are broadcast: rugby, cricket, soccer, basketball, volleyball, netball, athletics, hockey and wrestling/boxing/mixed martial arts. These sports were therefore classified as sports associated with the masses, as they were available to television viewers. The remaining sports were classified as highbrow/legitimate sports on the grounds of structural constraints.

For this definition, consumers were classified as univores if they had exclusive television consumption patterns, i.e. if they watched only high-brow/legitimate culture sports on television, or if they watched only sport that was associated with the masses. Conversely, consumers were classified as omnivores if they watched sport on television that was associated with the masses and high-brow/legitimate culture sports.

As highlighted by recent empirical research (Alderson et al., 2007; Chan \& Goldthorpe, 2007; Snowball et al., 2009; Antrobus \& Snowball, 2010), there is a need for research to explore new/sub classifications of the omnivore/univore classification, to provide a representational account for variations in consumption behaviour. Thus, this study considers other possible definitions/classifications of omnivore/univore that can be derived for the sporting context.

This study proposes four possible alternative indicators of sporting omnivores/univores. The first of these alternate definitions (hereafter referred to as Definition 1) pertains to the level at which the sport is played. The development of this definition is largely informed by Montgomery and Robinson (2008), where they noted the importance of differentiating between professional and amateur sport in examining consumption behaviour of art and non-art events. For this definition, spectators are classified as omnivores if they watch both professional and amateur cricket. However, if they watch only professional cricket, such spectators would be classified as univores.

The second alternate definition of omnivore and univore (hereafter referred to as Definition 2) considers whether spectators watch only cricket live (i.e. in attendance) or choose to watch cricket and other sports live. This definition was based on Peterson's (1992) definition of omnivores and univores. The derivation of this definition was also largely informed by the work of 
Snowball et al. (2009) and Lefevre and Ohl (2011:49). Snowball et al. (2009) defined univores as patrons with narrower cultural tastes (attending only one modern genre or two traditional genres of art), while omnivorous patrons were those that consumed a wider array (four or more types of art genres) of both popular and high cultural goods. Lefevre and Ohl (2011) classified individuals according to number of sporting activities that they participated in, where participation in two or three activities was indicative of low omnivority, whereas participation in four or more activities was indicative of high omnivority. Therefore, for this definition univores were spectators who choose to only watch cricket live to the exclusion of other sport (having a very narrow consumption demand for sport), while omnivores were those who choose to attend a wide range of sporting events (or general sports followers).

The third alternate (hereafter referred to as Definition 3) is similar to Definition 2, but considers the consumption of sport in the form of watching television. The derivation of this definition was similarly based on the notion of narrow/exclusive and wider/inclusive tastes as used by Peterson (1992) and Snowball et al. (2009). For this definition, participants were classified as univores if cricket was the only sport that they watched on television. Furthermore, participants who chose to consume only other sports (to the exclusion of cricket) were classified as univores owing to the exclusivity of their taste spectrum. Omnivores, on the other hand, were those participants that chose to watch a wide range of sport on television (indicative of an inclusive taste spectrum).

The final proposed classification (hereafter referred to as Definition 4) was again based on the spectrum of spectators' tastes, but considered whether the spectators classified themselves as general sports fans displaying a relatively wide taste spectrum and thus receiving omnivore status or only cricket fans displaying a relatively narrow taste spectrum and thus classified as univores. This definition encompassed all forms of sports consumption.

\section{DATA COLLECTION AND METHOD}

The data was collected by means of a questionnaire. The questionnaire was used to obtain a range of responses reflecting specific types of consumption behaviour of cricket spectators in the Eastern Cape. The questionnaire comprised 25 closed-ended questions with a Likert scale response format. The questionnaire further comprised five open-ended questions that were designed to generate qualitative data pertaining to spectators' perceptions of their consumption behaviour. Finally, five demographic questions were included, providing a basis upon which consumers could be classified. The questionnaire was administered at four different first class limited-over cricket matches played by the Chevrolet Warriors at Axxess DSL St Georges in Port Elizabeth on 7 November 2012, 18 November 2012, 23 November 2012 and 22 February 2013.

Purposive sampling was chosen to select participants for this study. As highlighted by Battaglia (2008), purposive sampling is a means of obtaining a sample, which is logically assumed representative of an entire population. In this instance, the selected sample was logically assumed to be representative of the cricket spectators in the Eastern Cape who watch the limitedovers format of the game. This specification was made owing to Date's (2012) comment that limited overs and test matches differ so significantly that they should essentially be viewed as separate sporting codes. The motive for the choice of the sampling technique was underpinned by the Laerd dissertation (2013), where it was noted that purposive sampling is an efficient means of sample selection when the population size is relatively small and the intention of the study is to make accurate statistical inferences from a sample to a population of interest. The data 
collected from the four matches was then pooled to obtain the final data set, with a final sample size of 438 respondents.

TABLE 1 presents some basic summary statistics. Roughly $71.69 \%$ of the sample was male, while the majority of the sample was White. The largest proportion of spectators was between the ages of 21 and 30 . The table also shows that $47.26 \%$ of the spectators had a post-secondary education. Finally, the majority of the sampled spectators earned a monthly net income between R0 and R20 000.

\section{TABLE 1: Summary descriptive statistics}

\begin{tabular}{|c|c|c|c|}
\hline Variables & & $N$ & $\%$ \\
\hline \multicolumn{4}{|l|}{ GENDER } \\
\hline & Male & 314 & 71.69 \\
\hline & Female & 124 & 28.31 \\
\hline \multicolumn{4}{|l|}{ RACE } \\
\hline & Black & 91 & 20.78 \\
\hline & White & 229 & 52.28 \\
\hline & Coloured & 98 & 22.37 \\
\hline & Indian & 20 & 4.57 \\
\hline \multicolumn{4}{|l|}{ AGE } \\
\hline & No Response & 3 & 0.68 \\
\hline & $11-20$ & 92 & 21.00 \\
\hline & $21-30$ & 145 & 33.11 \\
\hline & $31-40$ & 62 & 14.16 \\
\hline & $41-50$ & 67 & 15.30 \\
\hline & $51+$ & 69 & 15.75 \\
\hline \multicolumn{4}{|c|}{ HIGHEST LEVEL OF EDUCATION } \\
\hline & No Response & 4 & 0.91 \\
\hline & Primary education & 11 & 2.51 \\
\hline & Secondary education (no matric) & 69 & 15.76 \\
\hline & Matric & 147 & 33.56 \\
\hline & Post-secondary & 207 & 47.26 \\
\hline
\end{tabular}


PERSONAL MONTHLY NET INCOME

\begin{tabular}{lcc}
\hline No Response & 41 & 9.36 \\
R0 - R20 000 & 314 & 71.69 \\
R20 001 - R40 000 & 59 & 13.47 \\
R40 001 + & 24 & 5.48 \\
\hline
\end{tabular}

Source: Authors' analysis

Since the dependent variables are all in dichotomous form, binary probit models were estimated for the conventional definitions and for the alternate classifications. This was done to determine the probability of someone being an omnivore or univore for each particular definition, given specific individual characteristics. For each definition $i$, it is assumed that individuals are either classified as univores $\left(\right.$ definition $_{i}=1$ ) or omnivores (definition $n_{i}=0$ ). The model is specified as follows:

$$
\operatorname{Pr}\left(\text { definition }_{i}=1 \mid X i\right)=\Phi\left(\beta X^{\prime}\right)
$$

where $\Phi$ is the cumulative normal distribution function, $\beta$ is a vector of parameters, and the probability of being classified as a univore depends on a vector of explanatory variables $X$ '. The general model that is estimated takes the form:

$$
\operatorname{Pr}\left(\text { definition }_{i}=1 \mid X_{i}\right)=\beta_{0}+\beta_{1} \text { race }_{i}+\beta_{2} \text { gender }_{i}+\beta_{3} \text { age }_{i}+\beta_{4} \text { education }_{i}+\beta_{5} \text { income }_{i}
$$

where $u_{i}$ is the error term, and all other variables are discussed in the following section. All regressions were estimated using White heteroscedasticity-robust standard errors.

The variables included in the study were age, gender, race, highest level of education and personal monthly net income. The variable 'age' was measured in years, which consisted of the categories of 11-20, 21-30, 31-40, 41-50, and 51 and above. The gender variable was coded as 1 if a spectator was male and 0 for a female spectator. The race variable included 'Black', 'White', 'Coloured' and 'Indian'. The education variable denotes the highest level of education obtained and consisted of 'primary education', 'secondary education (but no matric)', 'matric', and 'postsecondary education'. Finally, personal monthly net income was measured in South African Rand and represented the spectators' reported personal monthly income after tax and other statutory deductions. The categories for personal monthly net income were R0-R20 000, R20 001-R40 000, and R40001+.

\section{RESULTS AND DISCUSSION}

TABLE 2 indicates the proportion of the sample classified as univores and omnivores respectively for the different definitions. From the omnivore/univore classification results, spectators were far more likely to be classified as omnivores than univores for all definitions. Overall, the vast majority of the sample was omnivores when spectators were classified according to the two conventional definitions. This finding suggests that for both forms of sports consumption, the majority of the spectators are more likely to have an inclusive sport taste spectrum. That is, spectators are more likely to consume sport across classifications (elitist sports and sport associated with the masses). A relatively greater proportion of the sample was classified as 
omnivores under the two conventional definitions than the four alternative definitions. This suggests that spectators are more likely to be classified as a univore under any of the alternate definitions than under the conventional definitions. These results suggest that generally it appears easier to classify omnivores and univores in terms of their taste spectrum as opposed to classifying them according to the 'eliteness/exclusivity' of the sports consumed.

\section{TABLE 2: Omnivore/univore classifications}

\begin{tabular}{|c|c|c|}
\hline & $N$ & $\%$ \\
\hline \multicolumn{3}{|c|}{ Conventional definition- Live } \\
\hline Univore & 30 & 6.85 \\
\hline Omnivore & 408 & 93.15 \\
\hline \multicolumn{3}{|c|}{ Conventional definition-TV } \\
\hline Univore & 12 & 2.74 \\
\hline Omnivore & 426 & 97.26 \\
\hline \multicolumn{3}{|l|}{ Definition 1} \\
\hline Univore & 98 & 22.37 \\
\hline Omnivore & 340 & 77.63 \\
\hline \multicolumn{3}{|l|}{ Definition 2} \\
\hline Univore & 85 & 19.41 \\
\hline Omnivore & 353 & 80.59 \\
\hline \multicolumn{3}{|l|}{ Definition 3} \\
\hline Univore & 37 & 8.45 \\
\hline Omnivore & 401 & 91.55 \\
\hline \multicolumn{3}{|l|}{ Definition 4} \\
\hline Univore & 39 & 8.90 \\
\hline Omnivore & 199 & 91.10 \\
\hline
\end{tabular}

Source: Authors' analysis

\subsection{Probit results for the conventional definitions}

In order to comment on whether or not sports consumption is tied up in social hierarchies, it is necessary to disaggregate the probability of a univore classification by all the explanatory variables that are employed in the study. The Pseudo $\mathrm{R}^{2}$ ranged between roughly $7.9 \%$ and $13.8 \%$ 
(TABLE 3). The Wald $\chi^{2}$ statistics show that for both conventional definitions, the explanatory variables jointly explain the variation in the probability of being classified as a univore $(p<.01)$.

TABLE 3: Probit results predicting the probability of a univore classification (conventional definitions)

\begin{tabular}{|c|c|c|c|c|}
\hline \multirow[t]{2}{*}{ Variable } & \multicolumn{2}{|c|}{ Conventional Definition - Live } & \multicolumn{2}{|c|}{ Conventional Definition- TV } \\
\hline & Coefficient & Marginal Effects & Coefficient & Marginal effects \\
\hline \multicolumn{5}{|l|}{ Race } \\
\hline \multirow[t]{2}{*}{ White } & 0.2063 & 0.0166 & -0.1791 & -0.0067 \\
\hline & $(0.2608)$ & & $(0.4396)$ & \\
\hline \multirow{2}{*}{ Coloured } & 0.1301 & 0.0097 & -0.5909 & -0.0313 \\
\hline & $(0.3169)$ & & $(0.4272)$ & \\
\hline \multirow[t]{2}{*}{ Indian } & -0.0459 & -0.0038 & -0.6477 & -0.0486 \\
\hline & $(0.4689)$ & & $(0.5941)$ & \\
\hline \multirow[t]{2}{*}{ Male } & $0.9562 * \star \star *$ & 0.1128 & 0.1033 & 0.0040 \\
\hline & $(0.2372)$ & & $(0.2994)$ & \\
\hline \multicolumn{5}{|l|}{ Age } \\
\hline \multirow[t]{2}{*}{$21-30$} & 0.0725 & 0.0056 & -0.6617 & -0.0312 \\
\hline & $(0.3459)$ & & $(0.4525)$ & \\
\hline \multirow[t]{2}{*}{$31-40$} & -0.3945 & -0.0405 & -0.7577 & -0.0530 \\
\hline & $(0.3918)$ & & $(0.4695)$ & \\
\hline \multirow[t]{2}{*}{$41-50$} & -0.3222 & -0.0313 & -0.4823 & -0.0270 \\
\hline & $(0.3214)$ & & $(0.5067)$ & \\
\hline \multirow[t]{2}{*}{$51+$} & -0.3056 & -0.0296 & -0.3327 & -0.0164 \\
\hline & $(0.3361)$ & & $(0.5877)$ & \\
\hline \multicolumn{5}{|l|}{ Education } \\
\hline \multirow[t]{2}{*}{ Some secondary } & $-3.9051 * \star \star$ & -0.9889 & $-3.7960 * \star \star$ & -0.9438 \\
\hline & $(0.2496)$ & & $(0.5619)$ & \\
\hline \multirow[t]{2}{*}{ Matric } & 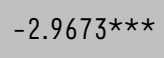 & -0.8193 & 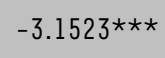 & -0.6432 \\
\hline & $(0.3169)$ & & $(0.4407)$ & \\
\hline \multirow[t]{2}{*}{ Post-secondary } & $-3.0876 * \star \star$ & -0.6792 & $-3.4970 \star \star \star$ & -0.6765 \\
\hline & $(0.3419)$ & & $(0.3916)$ & \\
\hline \multicolumn{5}{|l|}{ Income } \\
\hline$R 200001-R 40000$ & 0.1006 & 0.0075 & & \\
\hline
\end{tabular}




\begin{tabular}{|c|c|c|}
\hline Variable & Conventional Definition - Live & Conventional Definition- TV \\
\hline & $(0.3382)$ & \\
\hline \multirow[t]{2}{*}{ R40001+ } & -0.0122 & \\
\hline & $(0.4317)$ & \\
\hline \multirow[t]{2}{*}{ Constant } & 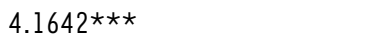 & $6.0867 \star \star \star$ \\
\hline & $(0.4047)$ & $(0.8063)$ \\
\hline $\mathrm{N}$ & 396 & 313 \\
\hline Wald $\chi^{2}$ & $816.23 * \star \star$ & 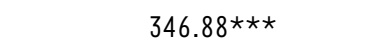 \\
\hline Pseudo $\mathrm{R}^{2}$ & 0.1378 & 0.0796 \\
\hline $\begin{array}{c}\% \text { Correctly } \\
\text { predicted }\end{array}$ & 93.18 & 97.12 \\
\hline
\end{tabular}

Source: Authors' analysis

Note: Values in brackets denote the robust standard errors. The omitted group for race is 'Black', for gender is 'female', for age is ' $11-20$ ', for education is 'primary education' and for income is 'R0-R20 000 '. $p<.01 * \star \star, p<.05^{\star \star}, p<.10 \star$. Note that 'Income' could not be included in the regression for the Conventional definition-TV. This is because only 12 individuals were classified as univores and of these 12 individuals, none fell into the top two income categories; hence, no comparison groups were available for income.

Statistically significant differences in the likelihood of univore status were found between males and females for live sports attendance, and this probability differed significantly across levels of education in both definitions. No significant differences were found in univore status across racial, age and income groups. The gender differences suggested that males were $11.28 \%$ more likely to be univores when compared to females, suggesting that males are more likely to display exclusivity in their choice of live sports consumption. Interestingly, unlike live sports consumption, the television consumption behaviour results for this definition showed no gender bias. Men may thus be relatively more likely to watch sport live when compared to women, whereas no such gender differences in the viewing of sport on television are evident.

Both conventional definitions showed a strong significant relationship with univore/omnivore status in terms of education. Individuals in all the education categories were significantly less likely to be classified as univores when compared to individuals with primary education. Univores, therefore, seem to be more likely to come from the lowest education level in line with existing empirical studies that increased education promotes or at least to some extent facilitates the movement away from univorous consumption behaviour towards omnivority (Sullivan \& KatzGerro, 2007; Van Eijck \& Leivens, 2008; Antrobus \& Snowball, 2010).

\subsection{Probit results for the alternative definitions}

The Pseudo $\mathrm{R}^{2}$ ranged between roughly $5.3 \%$ and $25.4 \%$ (TABLE 4). The Wald $\chi^{2}$ statistics show that for all four alternative definitions, the explanatory variables jointly explain the variation in the probability of being classified as a univore with all four statistics being significant at least at the $5 \%$ level. 


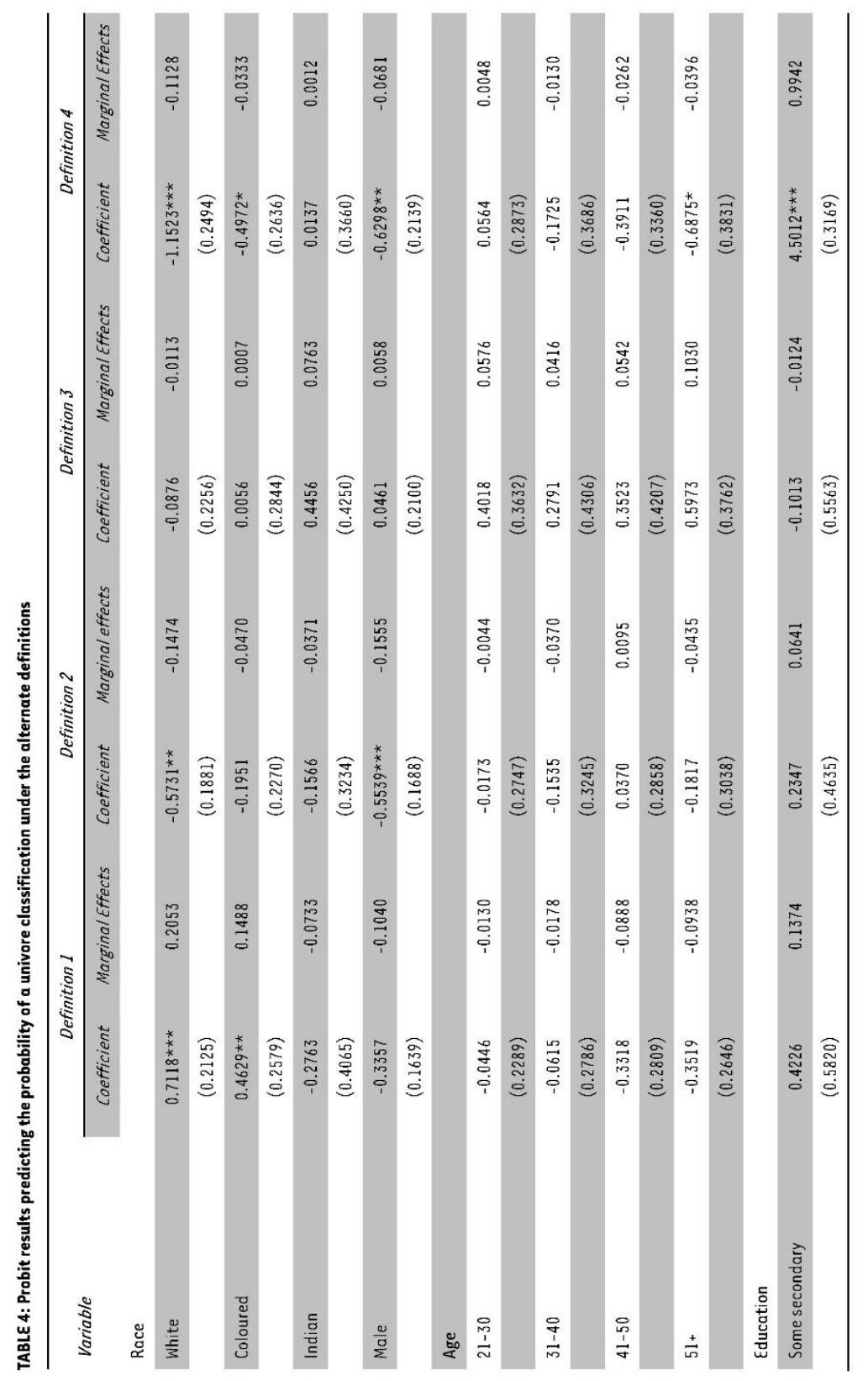




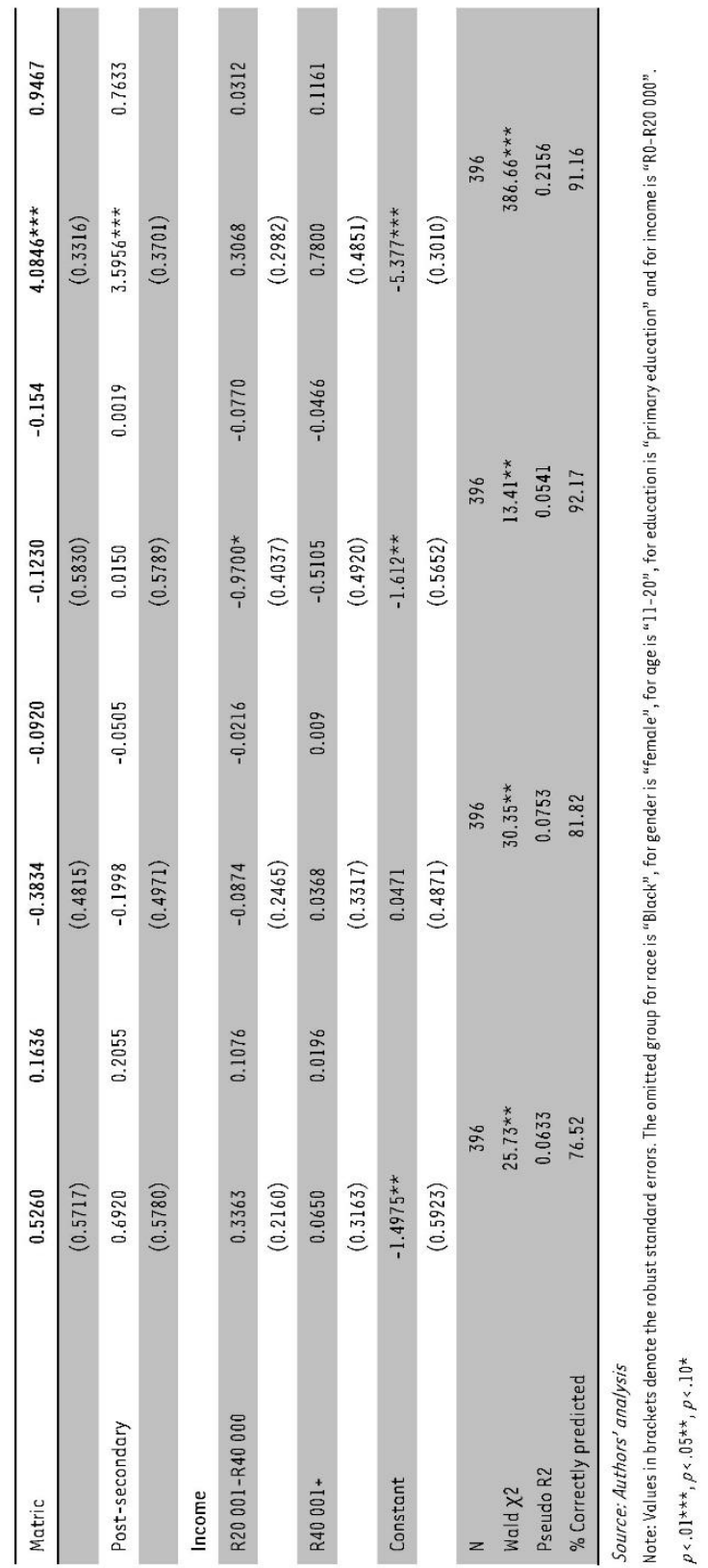


Males were about $15.55 \%$ and $6.81 \%$ less likely to be univores than females for Definitions 2 and 4 respectively. In terms of exclusivity of tastes, this finding is consistent with previous empirical research in the sporting context (Peterson, 1992; Lefevre \& Ohl, 2011; Warde, 2006; James \& Ridinger, 2002); however, it is inconsistent with the findings for the Conventional definition-live. The gender difference is, however, surprisingly, inconsistent with previous empirical research conducted in South Africa (Snowball et al., 2009; Antrobus \& Snowball, 2010).

For Definition 1, the results show that White and Coloured participants are on average $20.53 \%$ and $14.88 \%$ more likely to be classified as univores when compared to Black participants respectively.

Taking into account the empirical findings of Miles and Sullivan (2010), who reported a positive relationship between consumption behaviour and adult encouragement, Black parents (who were previously excluded from sports participation in the Apartheid era) may likely now be encouraging and supporting/spectating their children to get involved in a number of sports. However, for Definition 2, Whites were $14.74 \%$ less likely to be univores than Black participants, and for Definition 4, both White and Coloured participants were less likely to be univores than Blacks. A possible explanation for this finding could relate to the racial notion of the 'Black Diamond'. In contrast to Definition 1, White and Coloured participants were on average found less likely to be classified as a univore than Black participants were. This meant that White and Coloured participants were more likely to be general sports fans as opposed to only cricket fans, while the opposite was found to be true for Black participants. A possible explanation for this may again be attributed to the notion of the 'Black Diamond'. According to Chevalier (2014:4), the racial term 'Black Diamonds' refers to 'members of the new Black middle class - well-educated, professional and affluent.' Such individuals' consumption behaviour has been described as 'conspicuous consumption' (Sentleste, 2010:1) and has been argued to be a response to 'historical deprivation by groups who wish to affirm their new social standing' (Chevalier, 2014:6). With this in mind, it could explain why Black South Africans are likely to be more univorous and in a sense display 'exclusive tastes' by choosing to consume only cricket live as a means of affirming their postapartheid social standing.

Unlike the findings of both conventional definitions, under Definition 4, participants with either some secondary education, matric, or post-secondary levels of education were all on average found a lot more likely to be classified as univores than participants with primary education. However, the probability of being a univore under this definition decreases as the level of education increase. Thus, this finding presents a similar anomaly to that found for education under the Conventional definition-live. That is, that compared to all the other education groups, individuals with primary education are least likely to be univores. Underpinned by Bourdieu's (1984) line of argument, a possible explanation for this finding could be that individuals from the lowest level of education are associated with the least amounts of social capital (in this case specifically sporting knowledge), which is needed to appreciate the technical aspects of a sport. The results indicate that the probability of being a univore decreases as education increases, which essentially supports Peterson's (1992) hypothesis that individuals from higher education groups are likely to prefer a wider range of consumption.

The regression results for Definition 3 show that, unlike what was found for live sports consumption under Definition 2, gender and race were not significant predictors of univore status. The post-estimation $F$-tests indicate that no significant difference was found between any of the other explanatory variables, except between individuals in the R0-R20 000 and R20 001-R40 000 income categories $(p<.10)$. This finding suggests that the likelihood of middle-income (R20 001R40 000) earners being classified as a univore is $7.70 \%$ less than it is for lower income (R0-R20 
000) earners. In terms of age, only very marginal differences were found in Definition 4, with the only statistically significant difference being found between the youngest and oldest age categories. Individuals from the oldest age bracket $(51+)$ were $3.96 \%$ less likely to be classified as a univore when compared to individuals in the 11-20 years age bracket. Although not statistically significant, worth noting is that the size of the coefficients do suggest that older participants were on average less likely to be classified as univores than relatively younger cohorts. This suggests that on average, younger cohorts are more likely to be classified as cricket fans only, as opposed to general sports fans.

\section{CONCLUSION}

From an overall analysis of the findings on univore status under all the definitions, it is concluded that consumption behaviour of sport displays elements of social connotations. Sports consumption behaviour is also linked to educational hierarchies, but not significantly to levels of income. Given that education and income have generally been used as a proxy for social position, the findings of this study therefore do not support any previous empirical studies in its entirety. From an overall analysis of the findings, there are elements of racial differences in sports consumption behaviour in South Africa, suggesting that race plays a role in underpinning sports consumption behaviour. This finding is particularly pertinent given South Africa's history of racial divides. Considering the social tolerance implications that could stem from univorous consumption behaviour, it is suggested that stakeholders consider strategies to eradicate or minimise racial differences in consumption behaviour of sport. Suggestions of such strategies are to ensure that marketing is targeted at all racial groups (for example, using professional players of different races in marketing media or advertising of sport events in different South African languages). Based on the arguments of Bryson (1996) and Van Eijck and Leivens (2008), such strategies could encourage relatively more inclusive taste spectrums and in turn lead to higher levels of social tolerance in South Africa, particularly amongst racial groups.

It appears that the sports consumption behaviour of Eastern Cape cricket spectators is particularly unique when compared to the consumption behaviour of cultural consumers in South Africa and the consumption behaviour of sport internationally. The findings of the study differ from both the findings on sports consumption behaviour in other countries and from the findings of other forms of luxury activities consumption behaviour within South Africa.

An important limitation of this study is that even though the results may be representative of cricket spectators in the Eastern Cape, generalisation of the findings to consumers of the wider context is limited. The results of the study also pertain only to cricket spectators and therefore one cannot infer the findings to all sports spectators. The generalisation of the results is further limited in that data collection was conducted at the same ground and same catchment area. Furthermore, and related to this, is the limitation of the relatively small sample size of the study. Thus, it is suggested that, in order to attain results that can be generalised to South African sports consumers, future research should be conducted at a range of sporting events, hosted at a range of stadia throughout the country. Another shortcoming of the study could be the presence of common-method variance. Given that data collection is performed by means of a questionnaire only, there may be a spurious correlation between the variables in the study, which may in turn have caused the relationships between variables to be under- or overstated. 


\section{LIST OF REFERENCES}

Alderson, A., Junisbai, A. \& Heacock, I. (2007). Social status and cultural consumption in the United States. Poetics, 35, pp. 191-212.

Antrobus, R. \& Snowball, J. (2010). Physical theatre consumption and the advent of the 'festivore': A case study of audience attendance at the South African National Arts Festival. South African Theatre Journal, 24, pp. 326-343.

Battaglia, M.P. (2008). Purposive sampling. Available: http://srmo .sagepub.com/view/encyclopedia-of-survey-research-methods/n419.xml. (Accessed 12 0ctober 2013).

Bourdieu, P. (1984). Distinction: A social critique of the judgment of taste. London: Routledge.

Brember, A. (2009). Understanding consumer engagement with test match cricket multi-market study. Available: http://www.lords.org/data /files/mcc-mulitmarket-study-declining-test-matchattendance-2009-1-10342.pdf. (Accessed 14 March 2013).

Bryson, B. (1996). Anything but heavy metal: Symbolic exclusion and musical dislikes. American Sociological Review, 61(5), pp. 884-899.

Chan, T.W. \& Goldthorpe, J.H. (2005). The social stratification of theatre, dance and cinema attendance. Cultural Trends, 14(3), pp. 193-212.

Chan, T.W. \& Goldthorpe, J.H. (2007). Social stratification and cultural consumption: Music in England. European Sociological Review, 23, pp. 1-19.

Chevalier, S. (2014). The black diamonds: A South African phantasmagoria. Available: https://www.esrc.ac.uk/.../54a52031-5996-4ccl-a341-6f4c682ca265. (Accessed 10 February 2014).

Date, K. (2012). T20 (and ODI) is a separate sport and should be seen as such. A cricketing view. Available: http://cricketingview.blogspot.com/2012/09/t20-and-odi-is-separate-sport-andneeds.html. (Accessed 16 September 2014).

Eschenfelder, M.J. \& Li, M. (2007). Economics of sport. Morgantown: Fitness Information Technology. ETV. (2014). Sports. Available: http://www.etv.co.za/genre/sports. (Accessed 19 August 2014). James, J.D. \& Ridinger, L.L. (2002). Female and male sport fans: A comparison of sport consumption motives. Journal of Sport Behaviour, 25(3), pp. 260-280.

Kim, Y.K. \& Trail, G.T. (2010). Constraints and motivators: A new model to explain consumer behavior. Journal of Sport Management, 24, pp. 190-210.

Laerd Dissertation. (2013). Purposive sampling. Available: http://dissert ation.laerd.com/purposivesampling.php\#adv-dis. (Accessed 12 0ctober 2013).

Lamont, M. (1992). Money, morals and manners: The culture of the French and the American uppermiddle class. Chicago: University of Chicago Press.

Lefevre, B. \& Ohl, F. (2011). Consuming sports: distinction, univorism and omnivorism, Sport in Society: Cultures, Commerce, Media, Politics, 15, pp. 44-63.

Louw, A. (2010). Sports law in South Africa. Netherlands: Kluwer Law International.

Mehus, I. (2005). Distinction through sport consumption: Spectators of soccer, basketball and skijumping. International Review for the Sociology of Sport, 40, pp. 321-333. 
Miles, A. \& Sullivan, A. (2010). Understanding the relationship between taste and value in culture and sport. Available: https://www.gov.uk/

government/uploads/system/uploads/attachment_data/file/77966/DCMS_taste_and_value_docu ment.pdf. (Accessed 12 November 2013).

Montgomery, S. \& Robinson, M. (2008). Take me out to the opera: Are sports and arts compliments? Unpublished paper. Department of Economics. Mount Holyolk College.

Morgan, B. (2013). Cricket in South Africa. Available: http://www.

Southafrica.info/about/sport/cricket.html. (Accessed 14 March 2013).

Peterson, R.A. (1992). Understanding audience segmentation: From elite and mass to omnivore and univore. Poetics, 21(4), pp. 243-258.

Peterson, R.A. (2005). Problems in comparative research: The example of omnivourousness. Poetics, 33, pp. 257-282.

SABC Sport. (2014). Sport. Available: http://www.sabc.co.za/wps/wcm/connect 171fb25804525636d99da99a5ad025b24/SportSchedule+15+August+2014.pdf?MOD=AJPERES\&CACHEI $\mathrm{D}=71 \mathrm{fb} 25804525636 \mathrm{~d} 99 \mathrm{da} 99 \mathrm{a} 5 \mathrm{ad025b24}$. (Accessed 19 August 2014).

Scheetz, T.K., Dubin, R.A. \& Garbarino, E.C. (2014). A modern investigation of status consumption. Available: https://case.edu/artsci/dean /elf/documents/scheetzreport.pdf. (Accessed 25 June 2014).

Sentletse, D. (2010). In defence of conspicuous consumption. Available:

http://www.thoughtleader.co.za/sentletsediakanyo/2010/12/03/in-defence-of-conspicuousconsumption. (Accessed 10 February 2014).

Snowball, J.D., Jamal, M. \& Willis, K.G. (2009). Cultural consumption patterns in South Africa: An investigation of the theory of cultural omnivores. Social Indicators Research, 93(3), pp. 467-483.

South African Web. (2013). Sport and recreation in South Africa. Available:

http://www.southafricaweb.co.za/page/sport-and-recreation-south-africa. (Accessed 26 July 2013).

Statistics South Africa. (2012). Nationa/ accounts. Available: http://www.

statssa.gov.za/publications/Report-04-05-07/Report-04-05-072010.pdf. (Accessed 26 July 2013).

Suominen, S. (2007). Are the spectators of performing arts and the spectators of movies the same? Available: http://www.jace.gr.jp/ACEI2012/usb_program/pdf/ 7.2.2.pdf. (Accessed 10 November 2013).

Sullivan, 0. \& Katz-Gerro, T. (2007). The omnivore thesis revisited: Voracious cultural consumers. European Sociological Review, 23, pp. 123-137.

Supersport. (2014). Action attractions. Available: http://www.supersport.com/tv-guide [Accessed: 19 August 2014].

Szymanski, S. \& Kuypers, T. (1999). The economic design of sporting contests. Journal of Economic Literature, 41, pp. 1137-1187.

Thrane, C. (2001). Sport spectatorship in Scandinavia: A class phenomenon? International Review for the Sociology of Sport, 36, pp. 149-163.

Van Eijck, K. \& Leivens, J. (2008). Cultural omnivorousness as a combination of highbrow, pop and folk elements: The relation between taste patterns and attitudes concerning social integration. Poetics, 36, pp. 217-242. 
Warde, A. (2006). Cultural capital and the place of sport. Cultural Trends, 15(2-3), pp. 107-123.

White, P. and Wilson, B. (1999). Distinction in the stands: An investigation of Bourdieu's "habitus" socioeconomic status and sport spectatorship in Canada. International Review for the Sociology of Sport, 34, pp. 245-264.

Widdop, P. (2010). Sport, capital and consumption. Available:

http://www.humanities.manchester.ac.uk/socialchange/publications/working

/documents/SportCapitalandConsumption.pdf. (Accessed 16 0ctober 2010).

Widdop, P. \& Cutts, D. (2013). Social stratification and sports' participation in England. Leisure Sciences, 35, pp. 107-128.

Wilensky, H. L. (1964). Mass society and mass culture: Interdependence or independence? American Sociological Review, 29(2), pp. 173-197.

Wilson, T.C. (2002). The paradox of social class and sports involvement: The roles of cultural and economic capital. International Review for the Sociology of Sport, 37, pp. 5-16. 